\title{
Retrosplenial cortex is required for the retrieval of remote memory for auditory cues
}

\author{
Travis P. Todd, ${ }^{1,3}$ Max L. Mehlman, ${ }^{1,3}$ Christopher S. Keene, ${ }^{1,2}$ Nicole E. DeAngeli, ${ }^{1}$ \\ and David J. Bucci ${ }^{1}$ \\ ${ }^{1}$ Department of Psychological and Brain Sciences, Dartmouth College, Hanover, New Hampshire 03755, USA
}

\begin{abstract}
The restrosplenial cortex (RSC) has a well-established role in contextual and spatial learning and memory, consistent with its known connectivity with visuo-spatial association areas. In contrast, RSC appears to have little involvement with delay fear conditioning to an auditory cue. However, all previous studies have examined the contribution of the RSC to recently acquired auditory fear memories. Since neocortical regions have been implicated in the permanent storage of remote memories, we examined the contribution of the RSC to remotely acquired auditory fear memories. In Experiment 1, retrieval of a remotely acquired auditory fear memory was impaired when permanent lesions (either electrolytic or neurotoxic) were made several weeks after initial conditioning. In Experiment 2, using a chemogenetic approach, we observed impairments in the retrieval of remote memory for an auditory cue when the RSC was temporarily inactivated during testing. In Experiment 3, after injection of a retrograde tracer into the RSC, we observed labeled cells in primary and secondary auditory cortices, as well as the claustrum, indicating that the RSC receives direct projections from auditory regions. Overall our results indicate the RSC has a critical role in the retrieval of remotely acquired auditory fear memories, and we suggest this is related to the quality of the memory, with less precise memories being RSC dependent.
\end{abstract}

The retrosplenial cortex (RSC) is positioned at the interface between cortical sensory regions and various components of the hippocampal memory system, including the hippocampus proper as well as parahippocampal structures (van Groen and Wyss 1990, 1992, 2003; Sugar et al. 2011; van Strien et al. 2009). Its reciprocal connections with these areas suggest the RSC is well positioned to contribute to post-encoding processes such as memory storage and retrieval. Consistent with this, lesions of RSC carried out one day after conditioning impair the expression of contextual fear memory when rats are returned to the environment in which a footshock was previously delivered (Keene and Bucci 2008a,c). Furthermore, pharmacological inactivation of the RSC prior to a memory test session similarly disrupts the expression of contextual fear memory (Corcoran et al. 2011) and inhibitory avoidance memory (Katche et al. 2013). Notably, these effects were observed even when memory was tested several weeks after initial training, suggestive of a protracted involvement of RSC in memory recall (Corcoran et al. 2011; Katche et al. 2013). Furthermore, the expression of memory-associated immediate early genes (IEG; e.g., zif268), was found to be highest in RSC when a spatial memory retention trial took place $30 \mathrm{~d}$ after training compared with earlier time points, indicating that RSC is one of only a few regions that exhibit significant changes in activity particularly when memories are retrieved long after training (Maviel et al. 2004). The exact opposite pattern of IEG activity has been found in the hippocampus (e.g., Wiltgen et al. 2010).

The same studies that have revealed a role for RSC in contextual fear memory have consistently demonstrated that manipulations of RSC do not affect the expression of fear memory to a discrete auditory stimulus using a signaled fear conditioning procedure, i.e., a tone that was immediately followed by shock during

\footnotetext{
${ }^{2}$ Present address: Center for Memory and Brain, Boston University, Boston, Massachusetts, USA.

${ }^{3}$ These authors contributed equally to this work.

Corresponding author: travispetertodd@gmail.com

Article is online at http://www.learnmem.org/cgi/doi/10.1101/lm.041822. 116.
}

training (delay fear conditioning; Keene and Bucci 2008a,c; Corcoran et al. 2011; Kwapis et al. 2014, 2015). These findings suggest the RSC may be specifically involved in the storage and retrieval of long-term memories about the context, which is consistent with the well-documented visuo-spatial connectivity of the RSC (van Groen and Wyss 1990, 1992, 2003), although more recent studies have suggested that the RSC contributes to processing discrete cues under certain conditions (e.g., Kwapis et al. 2014, 2015). Nevertheless, prior studies of signaled fear conditioning have only examined the contribution of the RSC to recently acquired fear to a tone (Keene and Bucci 2008a,c; Kwapis et al. 2014, 2015); in contrast, no studies have considered whether manipulations of RSC affect the recall of long-term (remote) tone-specific memory. Since cortical regions are thought to be sites of storage for remote memories (e.g., Wiltgen et al. 2004; Frankland and Bontempi 2005), the retrieval of tone-specific memory may be more sensitive to disruptions of RSC at a remote time point.

The purpose of the present experiments was to examine RSC contributions to the remote retrieval of fear conditioned to an auditory cue in a signaled fear conditioning procedure. In Experiments 1 and 2, fear was conditioned to an auditory cue using delay (i.e., a tone immediately followed by shock), and trace (i.e., a tone followed by shock after an empty period of time) conditioning procedures, respectively. Lesions of the RSC (either electrolytic or neurotoxic) made $28 \mathrm{~d}$ after training (Experiment 1) and chemogenetic silencing of the RSC (Experiment 2) during retrieval reduced responding elicited by the auditory cue in a final test session. Thus, Experiments 1 and 2 demonstrated a critical role for the RSC in the retrieval of auditory fear memories using

\footnotetext{
(C) 2016 Todd et al. This article is distributed exclusively by Cold Spring Harbor Laboratory Press for the first 12 months after the full-issue publication date (see http://learnmem.cshlp.org/site/misc/terms.xhtml). After 12 months, it is available under a Creative Commons License (AttributionNonCommercial 4.0 International), as described at http://creativecommons. org/licenses/by-nc/4.0/.
} 
a signaled fear conditioning procedure. Finally, in Experiment 3, an anatomical tracing technique was used to determine how the RSC might receive auditory information.

\section{Results}

\section{Experiment 1: lesions of RSC impair retrieval of remotely acquired delay fear conditioning}

Although several studies have reported that the RSC is not involved in delay fear conditioning (Keene and Bucci 2008a,c; Corcoran et al. 2011; Kwapis et al. 2014, 2015), all studies have examined recently acquired fear to a tone. Since it is generally acknowledged that the neocortex is especially important for the permanent storage of remote memories (e.g., Wiltgen et al. 2004), we examined if the RSC contributed to remotely acquired delay fear conditioning.

All rats first received three tone-shock pairings in Context A. Following a 28-d retention interval rats received either sham, electrolytic (RSC-E), or neurotoxic (RSC-N) lesions of the RSC. Finally, to assess fear to the tone stimulus, there was a shockfree test session in which the tone was presented 20 times in Context B.

\section{Histology}

Bilateral damage of RSC was observed in all rats that received electrolytic lesions or neurotoxic lesions. Representative lesions are illustrated in Figure 1. The average area of RSC damaged on each section analyzed averaged $58.4 \%(\mathrm{SEM}=5.2)$ for Group RSC-E and $43.9 \%($ SEM $=8.7)$ for Group RSC-N. Damage to the RSC was present on $97.9 \%(\mathrm{SEM}=2.1)$ of the sections collected from each rat in Group RSC-E and 79.3\% (SEM = 6.9) of the sections collected from each rat in Group RSC-N, indicating that in both cases, damage extended throughout most of the rostro-caudal extent of RSC (Fig. 1). Minor damage to adjacent cortical regions (e.g., secondary motor cortex, cingulate cortex) was observed in both groups of lesioned rats (four out of seven rats in Group RSC-E on $36.3 \%$ (SEM = 7.8) of the sections analyzed, and three out of seven rats in Group RSC-N on 21\% (SEM = 5.1) of the sections analyzed). Two rats in each lesion group also exhibited slight damage to the cingulum bundle on $2-3$ sections.

\section{Behavior}

The level of post-shock freezing observed during training (left portion of Fig. 2) was comparable between control rats and the two RSC-lesion groups $(P>0.2)$, indicating that all rats acquired the conditioned fear response. Critically, rats in both lesion groups exhibited less freezing during the remote tone test in a novel context (middle portion of Fig. 2). A one-way ANOVA revealed a significant main effect of Group, $F_{(2,20)}=4.2, P<0.03$. Post hoc analyses revealed that freezing was reduced in both lesion groups compared to controls $(P<0.01$, RSC-E vs. Control; $P<0.04$, RSC-N vs. Control). There was no significant difference between the two lesion groups $(P>0.6)$.

There were also differences in freezing when rats were reexposed to the conditioning context one day prior to the tone test (right portion of Fig. 2), consistent with previously reported findings of Keene and Bucci (2008a,c). Post hoc analysis revealed that both RSC-lesion groups differed significantly from the control group $(P s<0.01)$, but not from each other $(P>0.7)$.
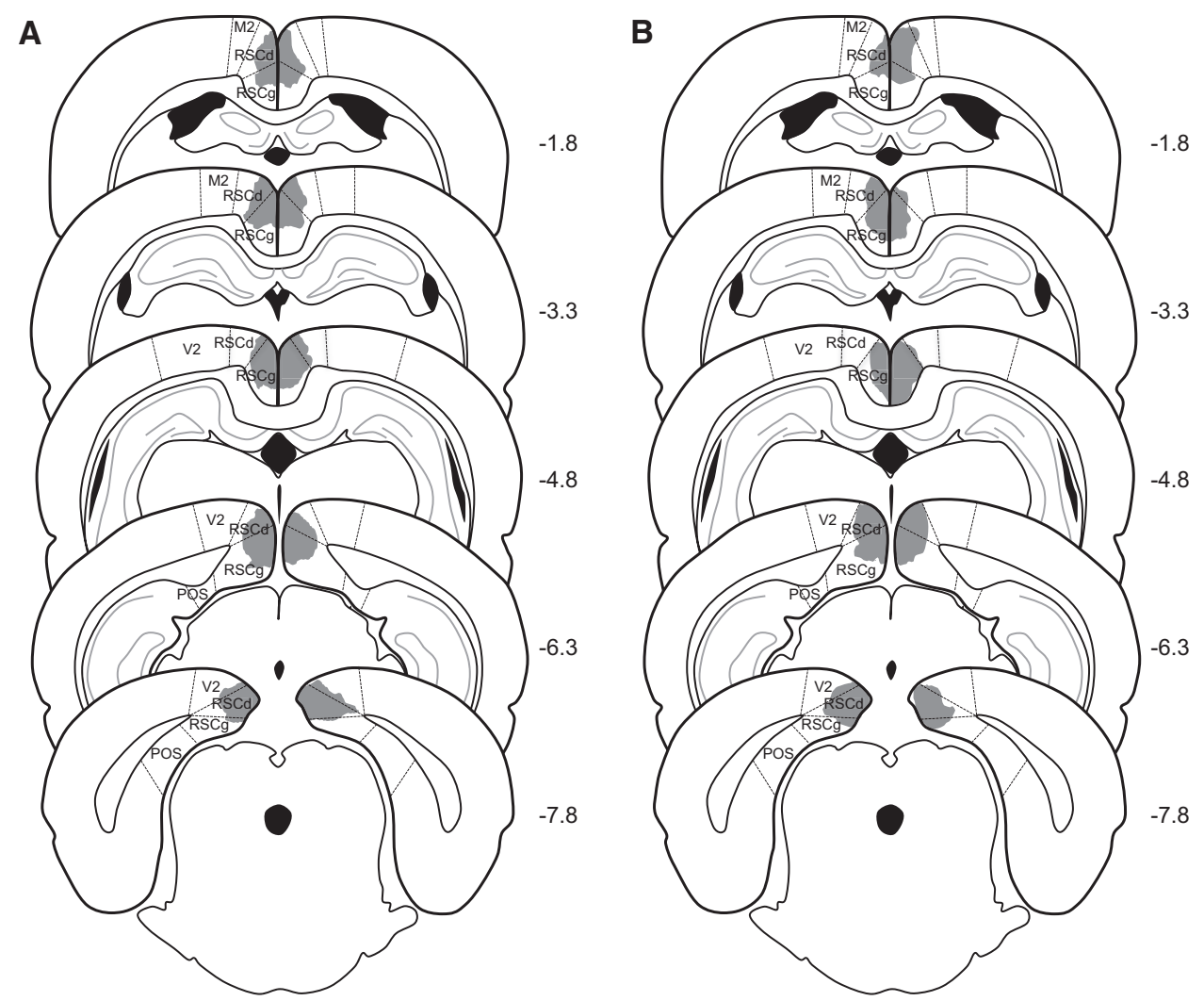

Figure 1. Schematic diagrams depicting the extent of representative electrolytic $(A)$ and neurotoxic $(B)$ lesions of the RSC in Experiment 1. The numbers adjacent to each section indicate the A/P position in mm relative to bregma based on Paxinos and Watson (2009). (M2) secondary motor cortex; (RSCd) retrosplenial cortex, dysgranular; (RSCg) retrosplenial cortex, granular; (V2) secondary visual cortex; (POS) post-subiculum. 


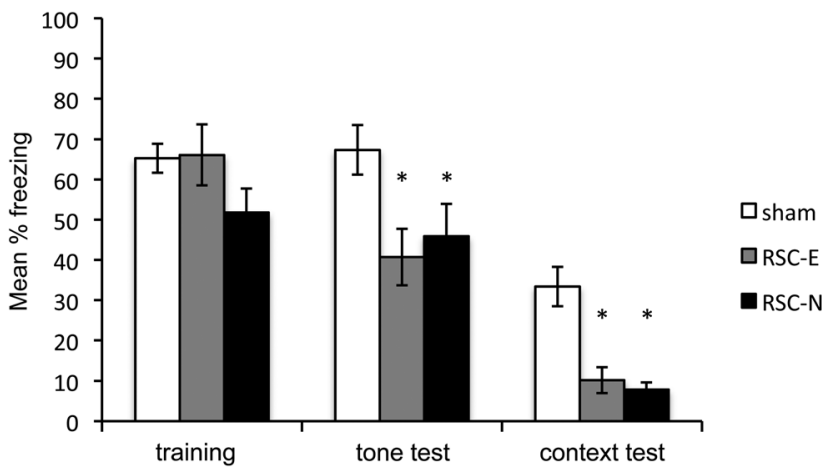

Figure 2. Results of Experiment 1. Freezing behavior during the prelesion training session and the post-lesion remote tone and remote context test sessions. Training $=$ mean percentage freezing during three post-shock periods. Tone test $=$ mean percentage freezing during 20 shock-free presentations of the tone in Context B. Context test $=$ mean percentage freezing during the 10 -min test in Context $A .\left(^{*}\right) P<0.05$.

Experiment 2: chemogenetic silencing of RSC neurons at test impairs retrieval of remotely acquired trace fear conditioning

In Experiment 1, lesions of the RSC $28 \mathrm{~d}$ after training reduced fear to an auditory cue. This is the first demonstration that the RSC contributes to delay fear conditioning, and directly contrasts with studies from several laboratories demonstrating the RSC is not involved in delay fear conditioning to an auditory cue (Keene and Bucci 2008a,c; Corcoran et al. 2011; Kwapis et al. $2014,2015)$. The fact that the RSC appears to be involved in delay fear conditioning that is remotely acquired compared with recently acquired is also consistent with the widely held view that areas of the neocortex are involved in storing and retrieving memories that were more remotely acquired (i.e., older memories).

The purpose of Experiment 2 was to extend this finding in two ways. First, to test the generalizability of the findings in Experiment 1, we used a trace fear conditioning preparation instead of delay fear conditioning. In contrast to delay fear conditioning, trace fear conditioning is dependent upon the RSC at recent time points (e.g., Kwapis et al. 2014, 2015). However, it is unknown whether the RSC contributes to the retrieval of trace fear conditioning at remote time points. Second, Experiment 2 used a chemogenetic approach to selectively inactivate RSC neurons only during the tone-memory retrieval session.

Prior to the start of the experiment, half of the rats were infused with AAV-hSyn-HA-hM4Di-IRES-mCitrine $(n=8$; Group Gi). This viral vector contained a gene for a synthetic inhibitory G-protein-coupled receptor (hM4Di) (Armbruster et al. 2007; Urban and Roth 2014) that suppresses neural activity when activated by systemic injection of clozapine- $n$-oxide (CNO; e.g., Robinson et al. 2014; Chang et al. 2015). Control rats were infused with a viral vector (AAV-hSyn-GFP) that did not contain the hM4Di receptor ( $n=8$; Group GFP). Following recovery, all rats received three tone-shock pairings in Context $A$. In this experiment, there was a 20-sec gap from tone offset to shock onset (e.g., Kwapis et al. 2014, 2015). The next day, rats were returned to Context A to assess recent context fear memory. Following a 28 - $d$ retention interval, there were two consecutive daily reexposures to Context A followed by a single exposure to Context $\mathrm{B}$. The first test session in Context A served as the remote context test. The additional exposure sessions to Context $\mathrm{A}$ and $\mathrm{B}$ were included in an effort to fully extinguish fear to the context alone. This reduction of context fear to very low levels has been suggested to increase sensitivity to differences in tone fear by eliminating any potential confounding effects of differential baseline fear levels (see Jacobs et al. 2010). All test sessions in Context A were preceded by intraperitoneal (IP) injections of CNO. There was then a final test of tone fear in Context B. During this session, all rats were injected with $\mathrm{CNO}$.

\section{Histology}

Virus expression for both groups is illustrated in Figure 3. In all animals, virus expression was confined almost entirely to the RSC and spanned the granular and dysgranular regions. Virusexpressing cells were observed in all layers and were most densely packed in layers II-IV. For Group Gi, the average percentage of RSC-containing sections with virus expression was 86.8 (SEM = 5.7), ranging from $53 \%-100 \%$, and the average virus expression rating was 2.5 , ranging from $1-4$. For Group GFP, the average percentage of RSC-containing sections with virus expression was 87.4 $(\mathrm{SEM}=5.9)$, ranging from $50 \%-100 \%$, and the average virus expression rating was 3 , ranging from $1-4$.

\section{Behavior}

Freezing during the training session, the remote tone test, and the remote context test is presented in Figure 4 . The level of postshock freezing observed during training (left portion of Fig. 4) was comparable between Group Gi and GFP $(P>0.37)$, indicating both groups acquired conditioning to a similar degree. Importantly, as shown in the middle portion of Figure 4, Group Gi froze less to the tone during the final remote tone test, compared with Group GFP, $F_{(1,14)}=7.34, P<0.05$. Thus, inactivation of the RSC reduced freezing during the retrieval of a remotely conditioned trace stimulus. Freezing during the remote context test is presented in the right portion of Figure 4. In contrast to Experiment 1, there were no differences when rats were reexposed to the original training context $(P=0.87)$.

In addition to the remote context shown in Figure 4, there were additional exposure sessions to Contexts A and B (not shown). The groups did not differ during the test of recent context memory in Context A $(P=0.89)$. During this test $(\mathrm{w} / \mathrm{CNO})$, the mean percentage freezing for $\mathrm{Gi}$ rats was $78.33(\mathrm{SEM}=6.67)$ and $79.50(\mathrm{SEM}=5.01)$ for GFP rats. Further, the groups did not differ during the second remote test in Context A $(P=0.98)$, or in the first exposure session to Context B $(P=0.29)$. For the second remote test in Context $\mathrm{A}(\mathrm{w} / \mathrm{CNO})$, the mean percentage freezing for $\mathrm{Gi}$ rats was $58.66(\mathrm{SEM}=8.31)$ and $58.83(\mathrm{SEM}=8.40)$ for GFP rats. For the first exposure to Context $\mathrm{B}$ (no $\mathrm{CNO}$ ), the mean percentage freezing to Context $\mathrm{B}$ was $43.66(\mathrm{SEM}=5.53)$ for Gi rats, and 33.33 (SEM = 7.76) for GFP rats.

The results of Experiment 2 extend the findings of Experiment 1 by demonstrating that the RSC is necessary for the retrieval of remote auditory fear memories established with a trace conditioning procedure. In contrast to Experiment 1, there were no reliable differences in freezing to the context alone. This was surprising given that context fear memory was affected in Experiment 1 and in prior studies (Keene and Bucci 2008a,c; Corcoran et al. 2011; Kwapis et al. 2015). There are several possible procedural explanations for this, as described later in the Discussion.

\section{Experiment 3: RSC receives projections from the primary and secondary auditory cortices, and the claustrum}

In Experiments 1 and 2, we observed reductions in fear elicited by an auditory stimulus when the RSC was either lesioned (Experiment 1) or temporarily inactivated (Experiment 2) several weeks after training. These findings, along with others (e.g., Gabriel et al. 1983; Kwapis et al. 2014, 2015), indicate the RSC is 

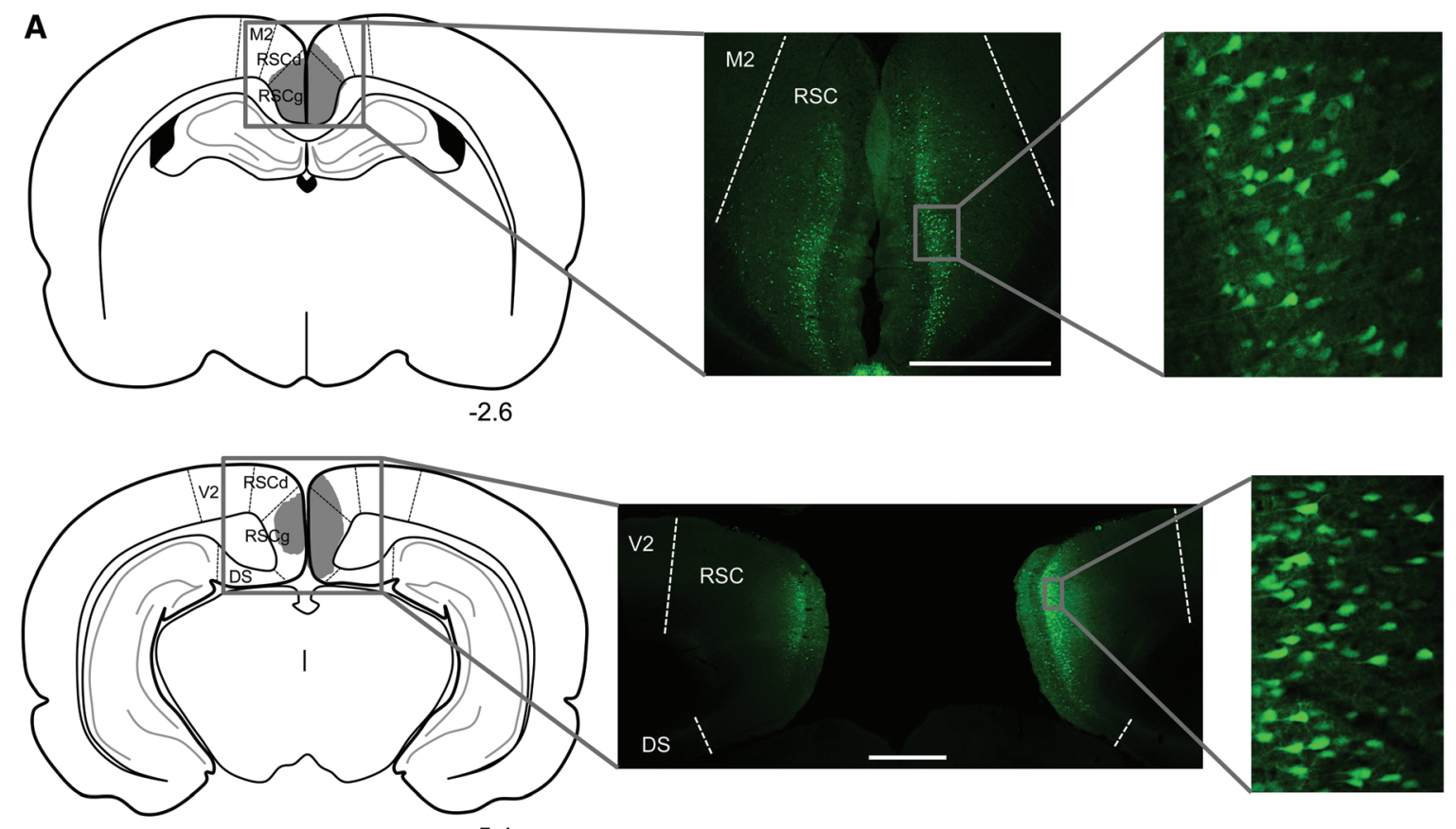

$-5.4$
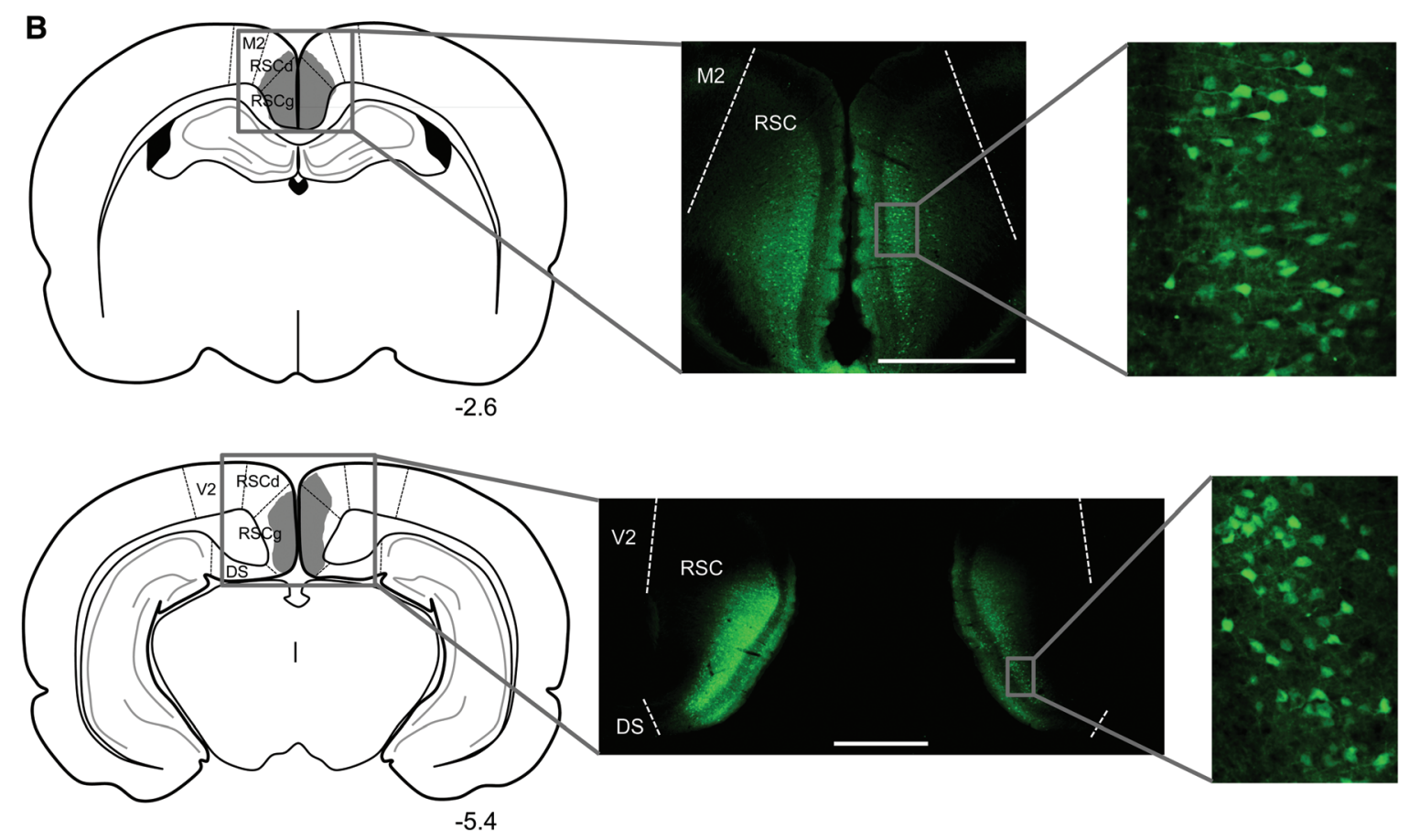

Figure 3. Virus expression in anterior and posterior portions of the RSC in a rat from group Gi $(A)$ and a rat from group GFP (B) in Experiment 2. Schematic diagrams in the left column depict the extent of virus expression within the RSC, with the numbers below each section indicating the $\mathrm{A} / \mathrm{P}$ position in $\mathrm{mm}$ relative to bregma based on Paxinos and Watson (2009). Low magnification (middle column) and high magnification (right column) images show virus-expressing cells. All scale bars represent $1 \mathrm{~mm}$. (M2) secondary motor cortex; (RSCd) retrosplenial cortex, dysgranular; (RSCg) retrosplenial cortex, granular; (V2) secondary visual cortex; (DS) dorsal subiculum.

involved in mnemonic processing related to auditory information. However, to date, no neuroanatomical studies have systematically investigated RSC connectivity with auditory regions. Thus, the purpose of the third experiment was to closely examine how the RSC might receive auditory information. To do so, a retrograde tracer was injected into the RSC and labeling patterns were assessed in structures involved in auditory processing and other cortical and subcortical regions. 


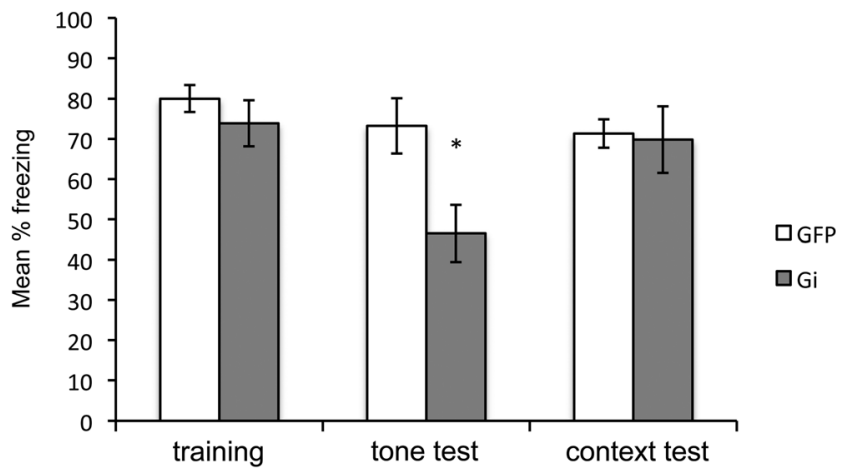

Figure 4. Results of Experiment 2. Freezing behavior during the training session and remote tone and remote context tests. Training $=$ mean percentage freezing during three post-shock periods. Tone test $=$ mean percentage freezing during 20 shock-free presentations of the tone in Context $\mathrm{B}$. Context test $=$ mean percentage freezing during the $10 \mathrm{~min}$ test in Context A. Prior to the remote tone and context tests, all rats were injected with CNO. Gi $=$ AAV-hSyn-HA-hM4Di-IRES-mCitrine and GFP $=$ AAV-hSyn-GFP. $(*) P<0.05$

\section{Injection sites}

Most injections were largely confined to either the granular or dysgranular region of the RSC, at anterior/posterior (A/P) positions ranging from $3.0-7.2 \mathrm{~mm}$ posterior to bregma. In some cases, tracer injections spanned both regions. At each injection site, tracer uniformly spread throughout a volume of tissue $\sim 1$ $\mathrm{mm}^{3}$. No injection extended into structures adjacent to the RSC (Fig. 5A,B)

\section{Labeling patterns}

We observed consistent labeling in the primary (Au1) and secondary (AuD and $\mathrm{AuV}$ ) auditory cortices of all animals, indicating direct projections from these cortices to the RSC. This labeling pattern was similar across animals with injections confined to either the granular or dysgranular region of the RSC, indicating that both regions receive similar auditory input. In contrast, we observed no labeled cells in upstream structures of the auditory pathway, including: the medial geniculate nucleus, inferior colliculus, superior olive, and ventral cochlear nucleus.

In the auditory cortex, labeled cells were confined to layer VI and were slightly more numerous in $\mathrm{AuD}$ and $\mathrm{AuV}$ compared with Au1 (Fig. 5A,C). These labeled cells generally displayed irregular, nonspherical shapes. Projections from the auditory cortex to the RSC were topographically organized; injections in anterior portions of the RSC (3.0-5.5 $\mathrm{mm}$ posterior to bregma) produced labeling primarily in anterior portions of the auditory cortex (3.0-4.5 $\mathrm{mm}$ posterior to bregma). Conversely, injections in posterior portions of the RSC (5.5-7.2 $\mathrm{mm}$ posterior to bregma) produced labeling primarily in posterior portions of the auditory cortex (4.5-5.5 $\mathrm{mm}$ posterior to bregma). Projections from the primary and secondary auditory cortices were mainly ipsilateral; in all animals, labeling was much more extensive in the same hemisphere as the injection site compared with the contralateral hemisphere (Fig. 5E). In animals with bilateral injections, doublelabeled cells (i.e., bilateral projections) were observed, but rare (Fig. 5E).

Consistent labeling was also observed in the claustrum, a structure involved in auditory processing (Spector et al. 1974; Olson and Graybiel 1980; Beneyto and Prieto 2001), indicating an additional route by which auditory information may enter the RSC. Projections from the claustrum terminated in both the granular and dysgranular regions of the RSC; injections confined to either of these regions produced similar labeling patterns in the claustrum. Compared with the auditory cortex, labeled cells in the claustrum were more numerous, more densely packed and generally more regular and spherical in shape.

Projections from the claustrum to the RSC were observed in all animals and were almost exclusively from posterior portions of the claustrum $(+2.8$ to $-1.0 \mathrm{~mm}$ relative to bregma); labeled cells were much more extensive in these portions compared to more anterior portions of the claustrum (3.0-4.2 $\mathrm{mm}$ anterior to bregma; Fig. 5A,D). Claustrum projections to the RSC were primarily ipsilateral; in all animals, labeled cells were much more numerous in the same hemisphere as the injection site compared with the contralateral hemisphere (Fig. 5E). In animals with bilateral injections, double-labeled cells were rare (Fig. 5E).

In all animals labeled cells were also observed in deep and superficial layers of the primary and secondary visual cortices, deep layers of the posterior parietal cortex and deep layers of the post-rhinal cortex (Fig. 5F). These corticocortical projections were primarily ipsilateral, but contralateral and bilateral projections were observed. Furthermore, labeled cells were observed in the anterodorsal and laterodorsal thalamic nuclei, dorsal subiculum, and deep layers of the post-subiculum; these projections were all exclusively ipsilateral (Fig. 5F). Finally, labeled cells were observed in the RSC; these intrinsic projections within the RSC were ipsilateral and contralateral. These findings are consistent with prior studies examining RSC connectivity (van Groen and Wyss 1990, 1992, 2003; Witter et al. 1990; Reep et al. 1994; Furtak et al. 2007; Sugar et al. 2011).

\section{Discussion}

The RSC has been the focus of an increasing amount of research, fueled in part by recent findings that it is among the first cortical regions to exhibit pathology associated with Alzheimer's disease (Minoshima et al. 1997; Buckner et al. 2005; Villain et al. 2008) and that it exhibits alterations in functional activity in persons with schizophrenia (Tendolkar et al. 2004; Bluhm et al. 2009). To date, most studies have focused on the involvement of RSC in spatial and contextual memory (for reviews, see Vann et al. 2009; Bucci and Robinson 2014; Miller et al. 2014; Todd and Bucci 2015), given the known connectivity between RSC and visuo-spatial cortical regions (van Groen and Wyss 1990, 1992, 2003). Here we extend this work by demonstrating for the first time that manipulations of RSC impair remote memory for discrete auditory cues.

The results of Experiments 1 and 2 indicate the RSC is necessary for the retrieval of an auditory fear memory acquired several weeks earlier. Importantly, the necessity of RSC for remote auditory fear memory was demonstrated with both permanent lesions (Experiment 1) and temporary chemogenetic inactivation specifically at the time of testing (Experiment 2). Moreover, the same effect on remote tone memory was obtained using both delay or trace fear conditioning procedures. Thus, the findings cannot be attributed to particularities of either the training methods or the procedures used to manipulate RSC, strengthening the conclusion that the RSC contributes critically to the retrieval of remotely acquired auditory fear memories.

Consistent with these findings, in Experiment 3, we identified projections from primary and secondary auditory cortices and the claustrum that could convey auditory information directly to RSC; these findings are consistent with preliminary reports of auditory projections to posterior portions of the cingulate cortex equivalent to the RSC (Vogt and Miller 1983). To our knowledge, this is the only study to systematically investigate the connectivity between RSC and auditory regions, and the 
A
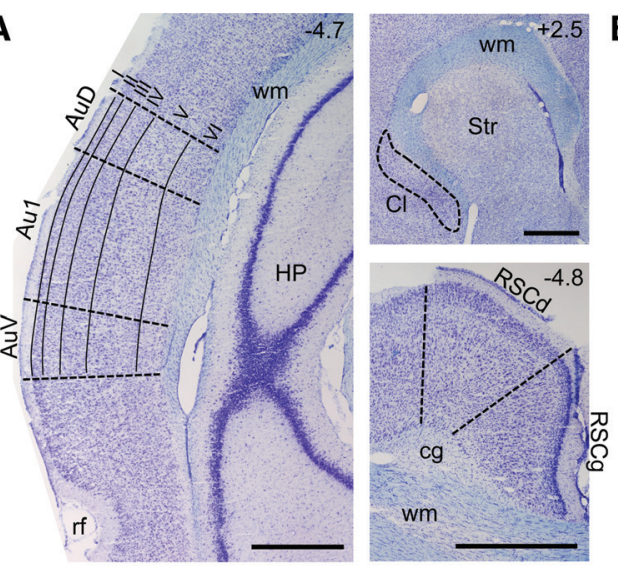

B
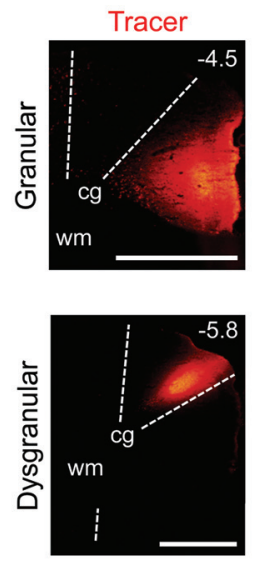

C
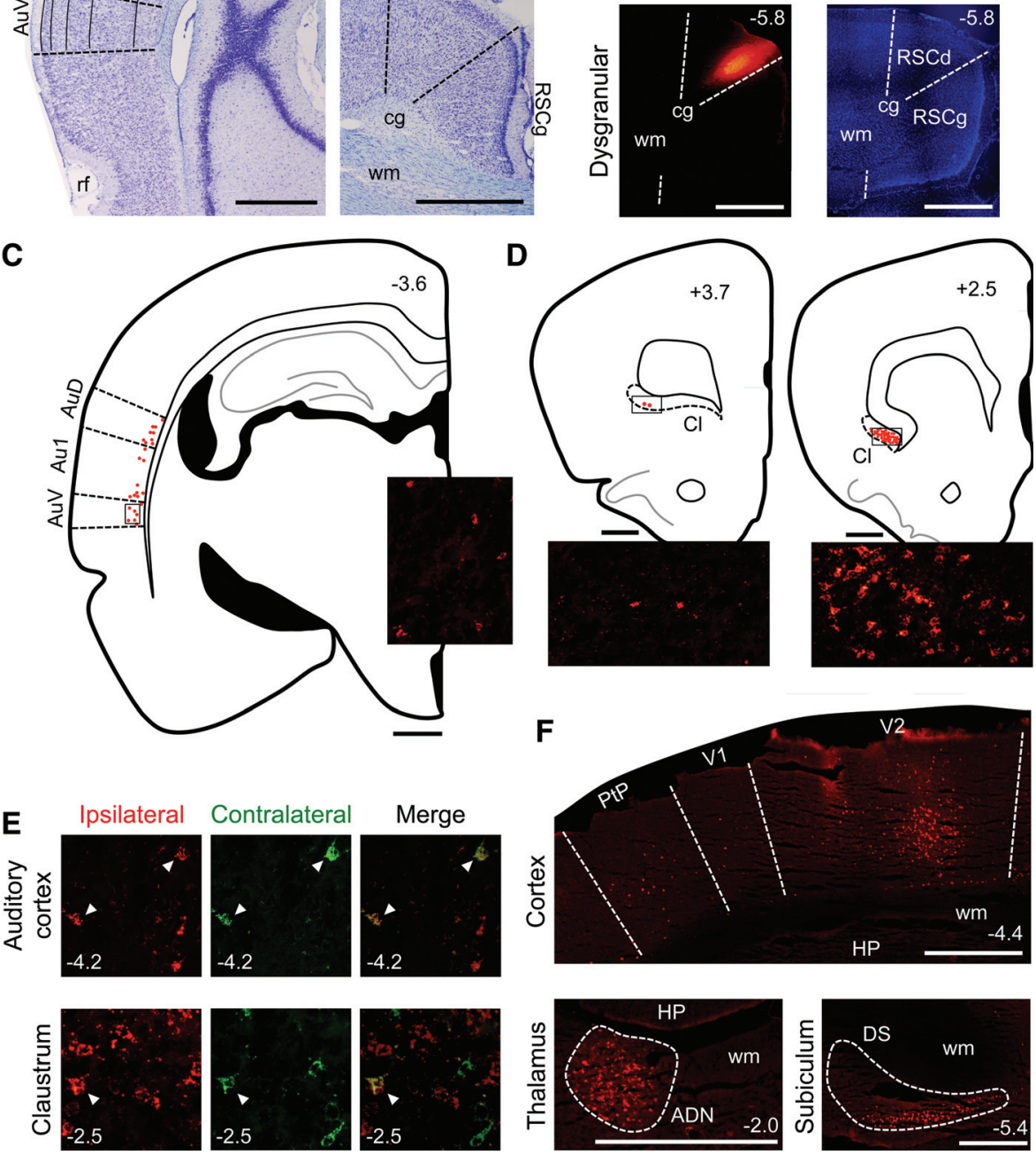

Figure 5. Results of Experiment 3. (A) Nissl-stained sections containing the auditory cortex (left), claustrum (upper right), or RSC (lower right). (B) Sections containing a tracer injection in the granular (top) or dysgranular (bottom) region of the RSC. The left column shows the tracer and the right column shows the DAPI stain. (C) Tracing of a section illustrating labeling in the auditory cortex following a tracer injection in the ipsilateral RSC. Each red dot represents one labeled cell. Inset image shows labeled cells in the region of the auditory cortex indicated by the rectangular outline on the tracing. (D) Tracings of sections illustrating labeling in anterior (left) and posterior (right) portions of the claustrum following a tracer injection in the ipsilateral RSC. Each red dot represents one labeled cell. Inset images show labeled cells in the regions of the claustrum indicated by the rectangular outlines on the tracings. (E) Bilaterally projecting cells in the auditory cortex (top) and claustrum (bottom). The left column shows cells projecting to the ipsilateral hemisphere and the middle column shows cells projecting to the contralateral hemisphere; these two images are merged in the right column. White arrows indicate doublelabeled (i.e., bilaterally projecting) cells. $(F)$ Other cortical and subcortical labeling patterns. The top image shows labeled cells in the primary and secondary visual cortices and the posterior parietal cortex, the lower left image shows labeled cells in the anterodorsal thalamic nucleus (outlined by the dashed line) and the lower right image shows labeled cells in the dorsal subiculum (outlined by the dashed line). The numbers in the corner of each image indicate the A/P position in $\mathrm{mm}$ relative to bregma, based on Paxinos and Watson (2009). All scale bars represent $1 \mathrm{~mm}$. (Au1) primary auditory cortex; (AuD) secondary auditory cortex, dorsal; (AuV) secondary auditory cortex, ventral; (rf) rhinal fissure; (wm) white matter; (HP) hippocampus; (Cl) claustrum; (Str) striatum; (RSCg) retrosplenial cortex, granular; (RSCd) retrosplenial cortex, dysgranular; (cg) cingulum; (V1) primary visual cortex; (V2) secondary visual cortex; (PtP) parietal cortex, posterior; (ADN) anterodorsal thalamic nucleus; (DS) dorsal subiculum. findings inform the RSC's role in mnemonic processing of auditory information. Although the "content" of the auditory information reaching the RSC remains to be determined, the fact that the RSC receives direct input from the auditory cortex and claustrum is consistent with its contribution to the retrieval of auditory fear memories.

The finding that retrieval of an auditory fear memory acquired several weeks earlier using delay fear conditioning procedures was impaired by damage to RSC (Experiment 1) is particularly intriguing in light of prior studies. Specifically, it has been consistently demonstrated that manipulations of RSC at a shorter training-testing interval (i.e., 1 d) have no impact on the retrieval of auditory fear memory (Keene and Bucci 2008a; Corcoran et al. 2011; Kwapis et al. 2014, 2015). Thus, the successful retrieval of memory for a discrete auditory stimulus becomes more dependent on RSC over time. This is consistent with the widely held view that over time, memories become stored more permanently in regions of the neocortex (e.g., Wiltgen et al. 2004; Winocur et al. 2010). It is also consistent with prior studies that have shown neural activity in the RSC is greater when mice recall an older spatial memory compared with a more recent memory (Maviel et al. 2004). The present data extend these findings by revealing that RSC is important for recalling remote memories for a discrete auditory stimulus, in addition to recalling spatial and contextual memories. Conversely, the hippocampus is typically not required for the retrieval of either recent or remote memories for a discrete auditory stimulus (Kim and Fanselow 1992; Anagnostaras et al. 1999; cf. Maren et al. 1997).

Nevertheless, it remains unclear if the development of RSC involvement over time also corresponds to a fundamental change in the nature of the auditory fear memory (e.g., see Winocur et al. 2010). For example, memory for contexts appears to become more general over time (see Riccio et al. 1984, 1999; Bouton et al. 1999a,b; Wiltgen et al. 2010). Importantly, generalization between discrete cues also increases over time, such that responding to different cues becomes more similar as time passes (see Bouton et al. 1999a). Thus, one possibility is that although recent auditory fear memories may be specific and detailed, older memories may become more general and less precise. Cortical involvement over time might thus reflect a change in the quality of the memory for a discrete cue, with detailed memories 
being RSC independent and less precise memories being RSC dependent. The inverse has been suggested with regard to the hippocampus and contextual fear memories; detailed memories require the hippocampus, whereas less precise memories for context can be retrieved without the hippocampus and presumably become more dependent upon the neocortex (see Wiltgen et al. 2010).

Interestingly, the retrieval of an auditory fear memory acquired in the trace fear conditioning procedure appears to be vulnerable to RSC manipulations regardless of whether it occurs $1 \mathrm{~d}$ (Kwapis et al. 2015) or several weeks (Experiment 2) after training. Indeed, Kwapis et al. (2015) found that blocking protein synthesis in RSC before training, or inhibiting NMDA receptors in RSC just before testing, impairs the retrieval of recently acquired fear to a trace conditioned tone. The reason why manipulations of RSC would impact recently acquired fear to a trace-conditioned tone but not a delay conditioned tone remains unclear and awaits further study. For example, it is possible that trace conditioning procedures might selectively engage processes that are RSC dependent, such as working memory (Keene and Bucci 2009) and timing (Todd et al. 2015). However, the involvement of the RSC in trace fear conditioning at both recent and remote time points might also be related to the precision of the trace fear memory. There is evidence that trace fear conditioning produces stronger generalization to other stimuli than delay fear conditioning (Honey and Hall 1992; see also Pavlov 1927, p. 113; Mackintosh 1974, p. 514). This suggests that from the outset trace fear memories are less precise than delay fear memories, and is thus consistent with the notion that RSC involvement is related to the quality of the memory. Nevertheless, these results contribute to a growing literature suggesting that different neurobiological mechanisms underlie trace and delay conditioning (e.g., Raybuck and Lattal 2014).

An unexpected finding in the present study was that remote context fear memory was impaired in Experiment 1 but not in Experiment 2. Indeed, in our own and others' prior studies, damage to RSC consistently impaired context fear memory (Keene and Bucci 2008a,c; Corcoran et al. 2011; Kwapis et al. 2015). Although it is not possible to conclusively state why there was no effect on context fear memory in Experiment 2, there are several possible explanations. For example, the lack of effect may have been an unintended consequence of the rats' prior experimental history since they had previously been in a context conditioning experiment (see Materials and Methods). The conditioning chambers used in the previous experiment had some unique features (i.e., visual and olfactory cues), but did share some general features with the current chambers, such as the overall dimensions. The prior exposure to a separate set of conditioning chambers may have protected against the effects of RSC inactivation, as has been observed with the hippocampus (Young et al. 1994). Nevertheless, the rats were experimentally naïve to the auditory cue at the start of Experiment 2, and chemogenetic manipulation of the RSC did produce a significant reduction in fear during the tone test session. Another explanation involves differences in the methods used to manipulate RSC in the two experiments (i.e., permanent electrolytic or neurotoxic lesions in Experiment 1, chemogenetics in Experiment 2). Specifically, in our laboratory, we have found that DREADD expression is not evident in all cells in the target region, and not all infected cells are inhibited by CNO (Chang et al. 2015). Thus, the DREADD manipulation in Experiment 2 may be tantamount to a "partial lesion" of the RSC, which may leave context fear memory intact. Indeed, it may be that other cortical areas have a more critical role than RSC in the retrieval/storage of remote context fear memory. For instance, prior studies have shown that the adjacent anterior cingulate cortex is necessary for expressing remote context fear memory (Frankland et al. 2004). It is also possible that the efficacy of the DREADD manipulation interacted with the prior training history of the subjects in Experiment 2. Importantly, however, the chemogenetic manipulation in Experiment 2 was sufficient to affect remote fear memory to the tone, leading to the intriguing notion that remote auditory memories may be more sensitive to RSC inactivation than remote context memories. This possibility awaits further study.

Although the RSC has a well-established role in spatial and contextual learning and memory, an emerging literature suggests it also has an important role in processing discrete cues (Gabriel et al. 1983; Keene and Bucci 2008b; Robinson et al. 2012 , 2014). The present experiments extended this work by examining the contribution of the RSC to remote memory retrieval, using a signaled fear conditioning procedure with an auditory cue. We suggest that RSC involvement in the retrieval of auditory fear memories is related to memory quality. When memories are detailed, such as in recently acquired delay fear conditioning (Keene and Bucci 2008a, 2008c; Corcoran et al. 2011; Kwapis et al. 2014, 2015), the RSC is not required. However, when memories are less precise, such as remotely acquired delay fear conditioning (Experiment 1), the RSC is required. The RSC is required for both recent and remote trace fear memories because trace fear conditioning is less precise from the outset (e.g., Honey and Hall 1992). This analysis is consistent with the notion that detailed memories are hippocampus dependent, and less detailed memories rely upon the neocortex (e.g., Wiltgen et al. 2010).

\section{Materials and Methods}

\section{Experiment 1}

Subjects

Twenty-three experimentally naïve male Long Evans rats weighing $\sim 275$ g were obtained from Harlan Laboratories (Indianapolis, IN). Rats were housed individually and allowed $7 \mathrm{~d}$ to acclimate to the vivarium with food available ad libitum (Purina standard rat chow; Nestle Purina, St. Louis, MO). Throughout the study, rats were maintained on a 14:10 light-dark cycle and monitored and cared for in compliance with Association for Assessment and Accreditation of Laboratory Animal Care guidelines and the Dartmouth College Institutional Animal Care and Use Committee.

\section{Surgery}

Subjects were anesthetized with isoflurane gas (1.5\%-3\% in oxygen) and placed in a Kopf stereotaxic apparatus (David Kopf Instruments). The skin was retracted and holes were drilled above each of the intended lesion sites using coordinates from the rat brain atlas of Paxinos and Watson (2009). The RSC-lesion target included the granular and dysgranular regions of RSC as defined by the Paxinos and Watson (2009) atlas. Twenty-eight days after behavioral training, rats received bilateral electrolytic (Group RSC-E) or neurotoxic (Group RSC-N) lesions of RSC ( $n=7$ per group) using the stereotaxic coordinates outlined in Table 1. The electrolytic lesions were produced by passing current $(2 \mathrm{~mA}$, $15 \mathrm{sec}$ per site) through an electrode that was epoxy-coated except for $1 \mathrm{~mm}$ at the tip. For the neurotoxic lesions, $0.3 \mu \mathrm{L}$ of ibotenic acid (10 $\mu \mathrm{g} / \mu \mathrm{L}$, Sigma Chemical Co.) was infused at each site using a $28 \mathrm{~g}$ Hamilton syringe (Hamilton Company, Reno, NV) connected to an automated pump (flow rate of $0.15 \mu \mathrm{L} / \mathrm{min}$; Stoelting). The syringe was left in place for $1 \mathrm{~min}$ before and 4 min after the infusion to control the spread of the neurotoxin and minimize diffusion up the needle track. Control rats $(n=9)$ received sham lesions of RSC consisting of a craniotomy in which shallow, nonpuncturing burr holes were made to minimize damage to underlying cortex. All rats were allowed to recover for $2 \mathrm{wk}$ before the subsequent memory test sessions. 
Table 1. Stereotoxic coordinates for retrosplenial cortex (RSC) lesions in Experiment 1

\begin{tabular}{clll}
\hline & $\mathbf{A} / \mathbf{P}$ & \multicolumn{1}{c}{$\mathbf{M} / \mathbf{L}$} & \multicolumn{1}{c}{$\mathbf{D} / \mathbf{V}$} \\
\hline Experiment 1 & & & \\
Electrolytic & -2.0 & \pm 0.3 & -1.6 and -2.5 \\
& -3.5 & \pm 0.4 & -1.8 and -2.5 \\
& -5.0 & \pm 0.4 and \pm 1.0 & -1.6 and -2.2 (medial), -1.6 (lateral) \\
& -6.5 & \pm 0.8 and \pm 1.4 & -1.6 and -2.2 (medial), -2.7 (lateral) \\
Neurotoxic & -8.0 & \pm 1.0 and \pm 2.0 & -2.0 (medial), -2.4 (lateral) \\
& -2.2 & \pm 0.5 & $-2.0(0.35 \mu \mathrm{L})$ \\
& -3.9 & \pm 0.5 & $-2.0(0.35 \mu \mathrm{L})$ \\
& -5.5 & \pm 0.5 and \pm 1.0 & $-1.8(0.35 \mu \mathrm{L})$ and $-2.6(0.20 \mu \mathrm{L})$ \\
& -6.7 & \pm 1.1 & $-2.2(0.35 \mu \mathrm{L})$ \\
& -8.0 & \pm 1.3 & $-1.8(0.30 \mu \mathrm{L})$ \\
\hline
\end{tabular}

All anterior/posterior $(A / P)$, medial/lateral $(M / L)$, and dorsal/ventral $(D / V)$ measurements are derived from bregma, midline, and skull surface, respectively (measurements are in $\mathrm{mm}$ ). (Medial) medial site; (lateral) lateral site.

\section{Behavioral apparatus}

Fear conditioning was conducted in standard operant conditioning chambers (ENV-007; $24 \mathrm{~cm} \mathrm{~W} \times 30.5 \mathrm{~cm} \mathrm{~L} \times 29 \mathrm{~cm} \mathrm{H}$; MED Associates) connected to a computer and enclosed in sound-attenuating chambers (ENV-017M; $66 \mathrm{~cm} \mathrm{~W} \times 56 \mathrm{~cm}$ $\mathrm{H} \times 56 \mathrm{~cm} \mathrm{D)}$ outfitted with an exhaust fan to provide airflow and background noise $(\sim 68 \mathrm{~dB})$. The operant chambers consisted of aluminum front and back walls, clear acrylic sides and top, and grid floors. A food cup was recessed in the center of the front wall ( $5 \mathrm{~cm}$ above the floor) and a panel light was located $\sim 15 \mathrm{~cm}$ above the grid floor centered over the food cup (neither the food cup nor the panel light was used in this study). A 2.8-W house light providing background illumination was mounted near the ceiling on the opposite wall. A speaker was located $15 \mathrm{~cm}$ above and to the right of the food cup and used to deliver a $1500 \mathrm{~Hz}$ tone for $10 \mathrm{sec}$ (the conditioned stimulus, CS). Delivery of a 1.0-mA, 1.0-sec constantcurrent shock through the grid floor of the operant chamber served as the unconditioned stimulus (US). Surveillance cameras located inside the sound-attenuating chambers were used to record the rats' behavior.

\section{Behavioral procedures}

All rats were trained in a standard fear conditioning task described previously (e.g., Maren et al. 1997; Arenos et al. 2006; Robinson et al. 2012). The training session consisted of three 10-sec presentations of the tone coterminating with the footshock. The interval from shock to the next tone (intertrial interval, ITI) was $64 \mathrm{sec}$. The first trial began $3 \mathrm{~min}$ after the rat was placed in the chamber. Two weeks after recovering from surgery, rats were re-exposed to the original training chamber for a 20 -min context test session during which no tones or shocks were presented. Twenty-four hours later, the tone test session was carried out by placing the rats in a novel context and presenting the tone 20 times (10 sec each, 30-sec ITI) beginning $30 \mathrm{sec}$ after the rat was placed in the chamber. Again, no shock was delivered during this test session. The novel context consisted of the original training chambers outfitted with plain white paper on the walls of the chamber to hide the recessed food cup and other stimuli present on the aluminum walls. Cardboard was also placed on top of the grid floor to provide a different tactile stimulus and a cup containing Vicks VapoRub (Proctor \& Gamble) and vinegar (Heinz) was placed in each sound-attenuating chamber to provide different olfactory cues. We have previously shown that rats exhibit very little freezing behavior to the new context itself (Arenos et al. 2006).

All rats received the context test session first, followed by the cue test session since this has previously been shown to be the optimal method for obtaining the most independent assessment of both auditory and contextual fear conditioning in the same rats (Maren et al. 1997). Nevertheless, our laboratory has previously examined whether the order of testing impacts levels of freezing to the context and tone during the test session and we have found identical results when the cue test session was conducted prior to the context test session (Arenos et al. 2006).

\section{Behavioral observations}

Freezing served as the index of conditioned fear and was operationally defined as total motor immobility except for breathing (Blanchard and Blanchard 1969; Fanselow 1980). On the training day, the incidence of freezing behavior was recorded during the 64 -sec period prior to the first trial (baseline freezing) and during the 64 -sec period following each trial (post-shock freezing). The rats' behavior was recorded every $8 \mathrm{sec}$ during the 64-sec epochs and mean freezing across the three post-shock epochs was calculated for each rat. Behavior was scored for the first 10 min of the context test session (behavior was scored every $8 \mathrm{sec}$ ). For the tone test session, freezing was recorded every 2 sec during each 10 -sec presentation of the tone. For each rat, the data were used to calculate the average freezing during the context test session and the average freezing during the tone test session. The frequency of freezing behavior was converted to a percentage of total observations. A single primary observer scored all of the behavioral data, while a second observer scored a subset of the data to assess objectivity. Both observers were blind to treatment condition and their observations were highly correlated $(r=0.9)$.

\section{Lesion verification}

After the behavioral procedures were completed, rats were deeply anesthetized with an overdose of sodium pentobarbital and transcardially perfused with $0.9 \%$ saline for $5 \mathrm{~min}$, followed by $10 \%$ buffered formalin. Brains were then removed and cryoprotected in $20 \%$ sucrose for $2 \mathrm{~d}$ prior to being sectioned. Brains were sectioned on a freezing microtome $(50 \mu \mathrm{m})$ and Nissl-stained using thionin. Coronal sections at $800-\mu \mathrm{m}$ intervals were used to assess the amount of tissue damage. Using StereoInvestigator software (version 6; Microbrightfield, Inc.) and a compound microscope (Axioskop I, Zeiss, Inc.), we identified gross tissue damage as necrosis, missing tissue, or marked thinning of the cortex. For each coronal section areal measurements were obtained using the StereoInvestigator Cavalieri estimator probe with $100-\mu \mathrm{m}$ grid spacing. Measurements included the total area of the target region and the area of the target region that exhibited gross tissue damage. In addition, we recorded the number of coronal sections on which RSC damage was present along the entire rostro-caudal extent of the region (a total of 33-36 sections for RSC-lesioned rats). The number of sections containing damage to regions outside of the target area was also recorded.

\section{Data analysis}

Analyses of freezing behavior were conducted using one-way analysis of variance (ANOVA) with Group (Control, RSC-E, RSC-N) as the between-subjects variable. Significant main effects were followed up with appropriate pair-wise comparisons using Fisher's PLSD test. An $\alpha$ level of 0.05 was adopted for all analyses.

\section{Experiment 2}

\section{Subjects}

The subjects were 16 male Long Evans rats weighing 350 g. They were purchased from the same vendor and maintained under the same conditions as those in the previous experiment. The subjects were not experimentally naïve; they had previously been trained in a contextual fear conditioning experiment where they had received exposure to the conditioning chambers and a single shock. 
Nevertheless, the rats were naïve to the auditory cue, which was of primary interest in the current experiment. Further, the conditioning chambers used in this experiment consisted of several features that differed from their previous experience (e.g., the specific visual and olfactory cues).

\section{Surgery}

All surgical procedures were identical to Experiment 1 with the following exceptions. Rats received 10 infusions (see Table 2; see also Robinson et al. 2014) of either AAV-hSyn-HA-hM4DiIRES-mCitrine ( $n=8$; Group Gi) or AAV-hSyn-GFP (Group GFP). Infusions were performed using a 26-gauge Hamilton syringe (Hamilton Company) connected to an automated pump (Stoelting). At each site, $0.8 \mu \mathrm{L}$ of the virus was infused at a rate of $0.15 \mu \mathrm{L} / \mathrm{min}$. The needle was left in place for $30 \mathrm{sec}$ before and 2 min following each infusion. The current experiment occurred $60 \mathrm{~d}$ following surgery, to allow ample time for the virus to fully express.

\section{Drug preparation}

A clozapine- $n$-oxide (CNO; Enzo Life Sciences) solution was prepared daily. $\mathrm{CNO}$ was first weighed and dissolved into dimethyl sulfoxide (DMSO; $1 \%$ of total solution volume) before being diluted in $0.9 \%$ sterile saline to a final concentration of $2 \mathrm{mg} / \mathrm{mL}$. CNO $(4 \mathrm{mg} / \mathrm{kg}$ ) was administered intraperitoneally $30 \mathrm{~min}$ prior to the appropriate behavior session.

\section{Behavioral apparatus}

Two sets of four chambers served as Context A and B (counterbalanced). Both sets of chambers were the same model (ENV-007) as those used as in Experiment 1, but were altered to have different visual and olfactory characteristics. One set of chambers was illuminated by a $2.8-\mathrm{W}$ bulb with a red cover, mounted to the ceiling of the sound-attenuating chamber. The second set of chambers was illuminated by the house light, as well as a panel light mounted $\sim 16 \mathrm{~cm}$ above the grid floor centered above the food cup. In these chambers the grids of the floor were staggered such that odd- and even-numbered grids were mounted in two separate planes, one $0.5 \mathrm{~cm}$ above the other. The staggered grid floor provided a distinct tactile feature. The ceiling, back wall, and door were covered with laminated black and white checkerboard paper (1-cm squares) to provide distinct visual cues. The physical identities of these chambers were counterbalanced as Contexts A and B. Because these two sets of chambers were located within the same room of the laboratory, in order to prevent diffusion of the olfactory cues we used one olfactory cue for Context

Table 2. Stereotoxic coordinates for Experiments 2 and 3

\begin{tabular}{cccc}
\hline & $\mathbf{A} / \mathbf{P}$ & $\mathbf{M} / \mathbf{L}$ & $\mathbf{D} / \mathbf{V}$ \\
\hline $\begin{array}{c}\text { Experiment 2 } \\
\text { Gi/GFP }\end{array}$ & -2.0 & \pm 0.3 & -2.6 \\
& -3.5 & \pm 0.3 & -2.4 \\
& -5.0 & \pm 0.3 & -2.6 \\
& -6.5 & \pm 1.0 & -2.4 \\
Experiment 3 & -8.0 & \pm 1.5 & -2.5 \\
Animal 1 & -3.0 & -0.4 & -1.2 \\
Animal 2 & -7.2 & -1.0 & -1.0 \\
& -3.5 & -0.5 & -1.5 \\
Animal 3 & -6.5 & -1.1 & -1.4 \\
& -3.0 & -0.3 & -1.5 \\
Animal 4 & -7.0 & -1.0 & -1.5 \\
Animal 5 & -3.75 & \pm 0.5 & -1.2 \\
\hline
\end{tabular}

All anterior/posterior $(\mathrm{A} / \mathrm{P})$ and medial/lateral $(\mathrm{M} / \mathrm{L})$ measurements are derived from bregma and midline, respectively. All dorsal/ventral $(D / V)$ measurements are derived from skull surface in Experiment 2 and cortical surface in Experiment 3. All measurements are in $\mathrm{mm}$.
A sessions, and a second olfactory cue for Context B sessions. During Context A sessions, $3 \mathrm{~mL}$ of $4 \%$ Anise solution was placed in the chamber tray below the grid floor, and in Context B sessions $3 \mathrm{~mL}$ of $8 \%$ coconut solution was used (McCormick \& Co. Inc.). The CS and US were the same as Experiment 2.

\section{Behavioral procedures and observations}

On the first day of the experiment, all rats received three toneshock pairings in Context A. The tone was $10 \mathrm{sec}$ in duration, and the shock occurred $20 \mathrm{sec}$ following the offset of the tone. Thus, there was a 20-sec trace interval (see Kwapis et al. 2014, 2015). The first trial began 3 min after the rat was placed in the chamber, and the interval from shock offset to the next tone onset was $64 \mathrm{sec}$. The subsequent day, all rats were returned to Context A for a 10-min context test session. Thirty minutes prior to this session, all rats were injected intraperitoneally $(4 \mathrm{mg} / \mathrm{kg}, 2 \mathrm{mg} / \mathrm{mL})$ $30 \mathrm{~min}$ prior to the session. Following the first context test, there was a 28 -d retention interval. For the next two consecutive days, rats were once again exposed to Context $\mathrm{A}$ following injections of $\mathrm{CNO}$. On the next day, all rats were exposed to Context B for a 10-min period (CNO was not injected). On the final day of the experiment, tone retrieval was tested in Context $\mathrm{B}$. All rats were first injected with CNO 30 min prior to being placed in the chambers. During the final test session, the 10 -sec tone was presented 20 times, followed by a 20 -sec gap, and then the ITI $(30 \mathrm{sec})$. No shocks were delivered during the final test session. The first trial began $30 \mathrm{sec}$ after placement into the chamber.

Freezing was indexed in the same fashion as Experiment 2. Observations between observers were highly correlated $(r>0.9)$. Analyses of freezing behavior were conducted using one-way analysis of variance (ANOVA) with Group (Gi vs. GFP) as the betweensubjects variable.

\section{Virus expression verification}

After the behavioral procedures were completed, rats were deeply anesthetized with an overdose of sodium pentobarbital and transcardially perfused with $0.9 \%$ saline for $5 \mathrm{~min}$, followed by $10 \%$ buffered formalin. Brains were then removed and cryoprotected in $20 \%$ sucrose for $2 \mathrm{~d}$ prior to being sectioned. Brains were sectioned on a freezing microtome (40 $\mu \mathrm{m}$ coronal sections) and mounted using a medium containing a fluorescent DAPI stain to enable the visualization of anatomical landmarks. For each animal, virus expression (Gi or GFP) was assessed using two approaches. First, all sections containing the RSC were examined using a fluorescent microscope (Olympus) equipped with filters for viewing yellow (Gi), green (GFP), and blue (DAPI) labeling and the percentage of sections in which virus expression was observed in the RSC was determined. Second, the level of virus expression in the RSC was rated on a scale of $0-5$, with 0 indicating no expression and 5 indicating complete expression throughout the entirety of the RSC. Finally, structures adjacent to the RSC were examined for virus expression.

\section{Experiment 3}

\section{Subjects}

Five female Long Evans rats weighing 275 g were obtained from Harlan Laboratories (Indianapolis, IN). Rats were housed in pairs with food and water available ad libitum. Throughout the study, rats were maintained on a 12:12 light-dark cycle and monitored and cared for in compliance with Association for Assessment and Accreditation of Laboratory Animal Care guidelines and the Dartmouth College Institutional Animal Care and Use Committee.

\section{Surgery}

Subjects were anesthetized with isoflurane gas (1\%-3\% in oxygen) then placed in a Kopf stereotaxic apparatus (David Kopf Instruments). An incision was made to expose the skull and small 
holes were drilled above each injection site. Each animal received two injections of the retrograde tracer cholera toxin subunit B (CTB; Thermo Fisher Scientific) into the RSC. The CTB was conjugated to a fluorescent molecule, either Alexa Fluor (AF) 488 (green) or AF 594 (red), and each animal received one injection of each color. Three animals each received two injections in the same hemisphere at different $\mathrm{A} / \mathrm{P}$ positions and two animals received a bilateral injection at a single A/P position (see Table 2). These 10 injection sites targeted the granular or dysgranular region of the RSC within the following range of coordinates: $3.0-7.2 \mathrm{~mm}$ posterior to bregma, $0.3-1.1 \mathrm{~mm}$ lateral to bregma, $1.0-1.5 \mathrm{~mm}$ ventral to the cortical surface (Paxinos and Watson 2009). Injections were delivered through a blunt 32-gauge cannula connected via polyethylene tubing to a $1 \mu \mathrm{L}$ Hamilton syringe (Hamilton Company) that was depressed by a syringe pump (Razel Scientific Instruments) at constant rate of $0.1 \mu \mathrm{L} / \mathrm{min}$ for $1-2$ $\mathrm{min}$. The cannula was left in place for $6 \mathrm{~min}$ after the injection to minimize diffusion of the tracer along the cannula track. Following surgery, all rats were housed individually and allowed to recover for $1 \mathrm{wk}$ prior to histological analyses. This 1 -wk duration allowed for optimal retrograde transport of the CTB (Conte et al. 2009).

\section{Histological analysis}

Rats were deeply anesthetized with an overdose of Euthasol and transcardially perfused with $500 \mathrm{~mL}$ of $0.9 \%$ saline followed by $500 \mathrm{~mL}$ of $4 \%$ paraformaldehyde (PFA). Brains were removed and post-fixed in 4\% PFA for $2 \mathrm{~d}$ then cryoprotected in $20 \%$ sucrose for $2 \mathrm{~d}$ prior to being sectioned on a cryostat $(30 \mu \mathrm{m}$ sections). For each brain, three series of coronal sections were taken, each composed of every third section. Two series were mounted using a medium containing a fluorescent DAPI stain; these sections were examined with a fluorescent microscope (Olympus) equipped with filters for viewing red (CTB AF 594), green (CTB AF 488), and blue (DAPI) labeling. These two series were used to visualize labeling patterns produced by the CTB as well as anatomical landmarks stained by DAPI. The third series was Nissl-stained with thionin and used to further examine anatomical landmarks and cytoarchitectural properties; these sections were examined with a light microscope (Leitz).

Each injection site was examined to determine (1) which region(s) of the RSC, granular and/or dysgranular, contained tracer and (2) where the injection was located along the $\mathrm{A} / \mathrm{P}$ axis of the RSC. Additionally, structures adjacent to the RSC were inspected for the presence of tracer. To determine whether the RSC receives auditory inputs, each structure in the auditory pathway was examined for labeling. The claustrum, a structure involved in auditory processing, was also inspected for labeling. Finally, labeling was examined in other structures known to project to the RSC. The location of each structure was determined by comparing DAPI- and Nissl-stained sections to a rodent brain atlas (Paxinos and Watson, 2009). Within the RSC and auditory cortex, borders between different regions and layers were identified based on their previously described cytoarchitectural properties (Games and Winer 1988; Roger and Arnault 1989; Van Groen and Wyss 1990, 1992, 2003; Winer 1992; Romanski and LeDoux 1993a,b; Smith et al. 2012).

Digital images were acquired from the fluorescent and light microscopes and imaging software was used to (1) uniformly adjust brightness and contrast levels, (2) merge images acquired with different filters, (3) overlay anatomical labels and borders, and (4) trace sections.

\section{Acknowledgments}

This work was supported by National Science Foundation grants IOS 00441934, IOS 0922075, and IOS 1353137 (D.J.B), and National Institutes of Health grants MH105125 (T.P.T.) and NS053907 (Jeffrey S. Taube). We thank Meghan C. Eddy for comments on a prior version of this manuscript, Matthew Y. Jiang for technical assistance, and Jeffrey S. Taube for support.

\section{References}

Anagnostaras SG, Maren S, Fanselow MS. 1999. Temporally graded retrograde amnesia of contextual fear after hippocampal damage in rats: within-subject examination. J Neurosci 19: 1106-1114.

Arenos JD, Musty RE, Bucci DJ. 2006. Blockade of cannabinoid CB1 receptors alters contextual learning and memory. Eur J Pharmacol 539: 177-183.

Armbruster BN, Li X, Pausch MH, Hertzile S, Roth BL. 2007. Evolving the lock to fit the key to create a family of $G$ protein-coupled receptors potently activated by an inert ligand. Proc Natl Acad Sci 104: $5163-5168$.

Beneyto M, Prieto JJ. 2001. Connections of the auditory cortex with the claustrum and the endopiriform nucleus in the cat. Brain Res Bull 54: 485-498.

Blanchard RJ, Blanchard DC. 1969. Crouching as an index of fear. J Comp Physiol Psychol 67: 370-375.

Bluhm RL, Miller J, Lanius RA, Osuch EA, Boksman K, Neufeld RW, Théberge J, Schaefer B, Williamson PC. 2009. Retrosplenial cortex connectivity in schizophrenia. Psychiatry Res 174: 17-23.

Bouton ME, Nelson JB, Rosas JM. 1999a. Stimulus generalization, context change, and forgetting. Psychol Bull 125: 171-186.

Bouton ME, Nelson JB, Rosas JM. 1999b. Resolution now! Reply to Riccio, Richardson, and Ebner (1999). Psychol Bull 125: 190-192.

Bucci DJ, Robinson S. 2014. Toward a conceptualization of retrohippocampal contributions to learning and memory. Neurobiol Learn Mem 116: 197-207.

Buckner RL, Snyder AZ, Shannon BJ, LaRossa G, Sachs R, Fotenos AF, Sheline YI, Klunk WE, Mathis CA, Morris JC, et al. 2005. Molecular, structural, and functional characterization of Alzheimer's disease: evidence for a relationship between default activity, amyloid, and memory. I Neurosci 25: 7709-7717.

Chang SE, Todd TP, Bucci DJ, Smith KS. 2015. Chemogenetic manipulation of ventral pallidal neurons reduces sign-tracking in rats. Eur J Neurosci 42: $3105-3116$.

Conte WL, Kamishina H, Reep RL. 2009. Multiple neuroanatomical tract-tracing using fluorescent Alexa Fluor conjugates of cholera toxin subunit B in rats. Nat Protoc 4: 1157-1166.

Corcoran KA, Donnan MD, Tronson NC, Guzmán YF, Gao C, Jovasevic V, Radulovic J. 2011. NMDA receptors in retrosplenial cortex are necessary for retrieval of recent and remote context fear memory. J Neurosci 31: $11655-11659$.

Fanselow MS. 1980. Conditional and unconditional components of post-shock freezing in rats. Pavlov J Biol Sci 15: 177-182.

Frankland PW, Bontempi B. 2005. The organization of recent and remote memories. Nat Rev Neurosci 6: 119-130.

Frankland PW, Bontempi B, Talton LE, Kaczmarek L, Silva AJ. 2004. The involvement of the anterior cingulate cortex in remote contextual fear memory. Science 304: 881-883.

Furtak SC, Wei S, Agster KL, Burwell RD. 2007. Functional neuroanatomy of the parahippocampal region in the rat: the perirhinal and postrhinal cortices. Hippocampus 17: 709-722.

Gabriel M, Lambert RW, Foster K, Orona E, Sparenborg S, Maiorca RR. 1983. Anterior thalamic lesions and neuronal activity in the cigulate and retrosplenial cortices during discriminative avoidance behavior in rabbits. Behav Neurosci 97: 675-696.

Games KD, Winer JA. 1988. Layer V in rat auditory cortex: projections to the inferior colliculus and contralateral cortex. Hear Res 34: 1-25.

Honey RC, Hall G. 1992. CS memory after trace conditioning. Learn Motiv 23: $145-155$.

Jacobs NS, Cushman JD, Fanselow MS. 2010. The accurate measurement of fear memory in Pavlovian conditioning: Resolving the baseline issue. J Neurosci Methods 190: 235-239.

Katche C, Dorman G, Slipczuk L, Cammarota M, Medina JH. 2013. Functional integrity of the retrosplenial cortex is essential for rapid consolidation and recall of fear memory. Learn Mem 20: 170-173.

Keene CS, Bucci DJ. 2008a. Contributions of the retrosplenial and posterior parietal cortices to cue-specific and contextual fear conditioning. Behav Neurosci 122: 89-97.

Keene CS, Bucci DJ. 2008b. Involvement of retrosplenial cortex in processing multiple conditioned stimuli. Behav Neurosci 122: 651-658.

Keene CS, Bucci DJ. 2008c. Neurotoxic lesions of retrosplenial cortex disrupt signaled and unsignaled contextual fear conditioning. Behav Neurosci 122: 1070-1077.

Keene CS, Bucci DJ. 2009. Damage to the retrosplenial cortex produces specific impairments in spatial working memory. Neurobiol Learn Mem 91: $408-414$

Kim JJ, Fanselow MS. 1992. Modality-specific retrograde amnesia of fear. Science 256: 675-677.

Kwapis JL, Jarome TJ, Lee JL, Gilmartin MR, Helmstetter FJ. 2014. Extinguishing trace fear engages the retrosplenial cortex rather than the amygdala. Neurobiol Learn Mem 113: 41-54. 
Kwapis JL, Jarome TJ, Lee JL, Helmstetter FJ. 2015. The retrosplenial cortex is involved in the formation of memory for context and trace fear conditioning. Neurobiol Learn Mem 123: 110-116.

Mackintosh NJ. 1974. The psychology of animal learning. Academic Press, London.

Maren S, Aharonov G, Fanselow MS. 1997. Neurotoxic lesions of the dorsal hippocampus and Pavlovian fear conditioning in rats. Behav Brain Res 88: $261-274$.

Maviel T, Durkin TP, Menzaghi F, Bontempi B. 2004. Sites of neocortical reorganization critical for remote spatial memory. Science 305: 96-99.

Miller AMP, Vedder LC, Law M, Smith DM. 2014. Cues, context, and long-term memory: the role of the retrosplenial cortex in spatial cognition. Front Hum Neurosci 8: 1-15.

Minoshima S, Giordani B, Berent S, Frey KA, Foster NL, Kuhl DE. 1997. Metabolic reduction in the posterior cingulate cortex in very early Alzheimer's disease. Ann Neurol 42: 85-94.

Olson CR, Graybiel AM. 1980. Sensory maps in the claustrum of the cat. Nature 288: 479-481.

Pavlov IP. 1927. Conditioned reflexes. (G. V. Anrep, translation). Oxford University Press, London.

Paxinos G, Watson C. 2009. The rat brain in stereotaxic coordinates: compact sixth edition. Elsevier, London.

Raybuck JD, Lattal KM. 2014. Bridging the interval: theory and neurobiology of trace conditioning. Behav Processes 101: 103-111.

Reep RL, Chandler HC, King V, Corwin JV. 1994. Rat posterior parietal cortex: topography of corticocortical and thalamic connections. Exp Brain Res 100: $67-84$.

Riccio DC, Richardson R, Ebener DL. 1984. Memory retrieval deficits based upon altered contextual cues: a paradox. Psychol Bull 96: 152-165.

Riccio DC, Richardson R, Ebener DL. 1999. The contextual change paradox is still unresolved: comment on Bouton, Nelson, and Rosas (1999). Psychol Bull 125: 187-189.

Robinson S, Keene CS, Iaccarino HF, Duan D, Bucci DJ. 2012. Involvement of retrosplenial cortex in forming associations between multiple sensory stimuli. Behav Neurosci 125: 578-587.

Robinson S, Todd TP, Pasternak AR, Luikart BW, Skelton PD, Urban DJ, Bucci DJ. 2014. Chemogenetic silencing of neurons in the retrosplenial cortex disrupts sensory preconditioning. J Neurosci 34: 10982-10988.

Romanski LM, LeDoux JE. 1993a. Organization of rodent auditory cortex: anterograde transport of PHA-L from MGv to temporal neocortex. Cereb Cortex 3: 499-514.

Romanski LM, LeDoux JE. 1993b. Information cascade from primary cortex to the amygdala: corticocortical and corticoamygdaloid projections of temporal cortex in the rat. Cereb Cortex 3: 515-532.

Roger M, Arnault P. 1989. Anatomical study of the connections of the primary auditory area in the rat. J Comp Neurol 287: 339-356.

Smith PH, Uhlrich DJ, Manning KA, Banks MI. 2012. Thalamocortical projections to rat auditory cortex from the ventral and dorsal divisions of the medial geniculate nucleus. J Comp Neurol 520: 34-51.

Spector I, Hassmannova J, Albe-Fessard D. 1974. Sensory properties of single neurons of cat's claustrum. Brain Res 66: 39-65.

Sugar J, Witter MP, van Strien NM, Cappaert NL. 2011. The retrosplenial cortex: intrinsic connectivity and connections with the (para)hippocampal region in the rat. An interactive connectome. Front Neuroinform 5: 7.
Tendolkar I, Weis S, Guddat O, Fernández G, Brockhaus-Dumke A, Specht K, Klosterkötter J, Reul J, Ruhrmann S. 2004. Evidence for a dysfunctional retrosplenial cortex in patients with schizophrenia: a functional magnetic resonance imaging study with a semanticperceptual contrast. Neurosci Lett 369: 4-8.

Todd TP, Bucci DJ. 2015. Retrosplenial cortex and long-term memory: molecules to behavior. Neural Plast 2015: 414173.

Todd TP, Meyer HC, Bucci DJ. 2015. Contribution of retrosplenial cortex to temporal discrimination learning. Hippocampus 25: 137-141.

Urban DJ, Roth BL. 2014. DREADDs (Designer Receptors Exclusively Activated by Designer Drugs): chemogenetic tools with therapeutic utility. Annu Rev Pharmacol Toxicol 55: 399-417.

van Groen T, Wyss JM. 1990. Connections of the retrosplenial granular a cortex in the rat. J Comp Neurol 300: 593-606.

van Groen T, Wyss JM. 1992. Connections of the retrosplenial dysgranular cortex in the rat. J Comp Neurol 315: 200-216.

van Groen T, Wyss JM. 2003. Connections of the restrosplenial granular b cortex in the rat. J Comp Neurol 463: 249-263.

Vann SD, Aggleton JP, Maguire EA. 2009. What does the retrosplenial cortex do? Nat Rev Neurosci 10: 792-803.

van Strien NM, Cappaert NL, Witter MP. 2009. The anatomy of memory: an interactive overview of the parahippocampal-hippocampal network. Nat Rev Neurosci 10: 272-282.

Villain N, Desgranges B, Viader F, De La Sayette V, Mézenge F, Landeau B, Baron JC, Eustache F, Chételat G. 2008. Relationships between hippocampal atrophy, white matter disruption, and gray matter hypometabolism in Alzheimer's disease. J Neurosci 28: 6174-6181.

Vogt BA, Miller MW. 1983. Cortical connections between rat cingulate cortex and visual, motor, and postsubicular cortices. J Comp Neurol 216: 192-210.

Wiltgen BJ, Brown RA, Talton LE, Silva AJ. 2004. New circuits for old memories: the role of the neocortex in consolidation. Neuron 44: $101-108$.

Wiltgen BJ, Zhou M, Cai Y, Balaji J, Karlson MG, Parivash SN, Weidong L, Silva AJ. 2010. The hippocampus plays a selective role in the retrieval of detailed contextual memories. Curr Biol 20: 1336-1344.

Winer JA. 1992. The functional architecture of the medial geniculate body and the primary auditory cortex. In The mammalian auditory pathway: neuroanatomy (ed. Webster DB, Popper AN, Fay RR), pp. 222-409. Springer-Verlag, New York.

Winocur G, Moscovitch M, Bontempi B. 2010. Memory formation and long-term retention in humans and animals: convergence towards a transformation account of hippocampal-neocortical interactions. Neuropsychologia 48: 2339-2356.

Witter MP, Ostendorf RH, Groenewegen HJ. 1990. Heterogeneity in the dorsal subiculum of the rat. Distinct neuronal zones project to different cortical and subcortical targets. Eur J Neurosci 2: 718-725.

Young SL, Bohenek DL, Fanselow MS. 1994. NMDA processes mediate anterograde amnesia of contextual fear conditioning induced by hippocampal damage: immunization against amnesia by context preexposure. Behav Neurosci 108: 19-29.

Received January 26, 2016; accepted in revised form March 7, 2016. 


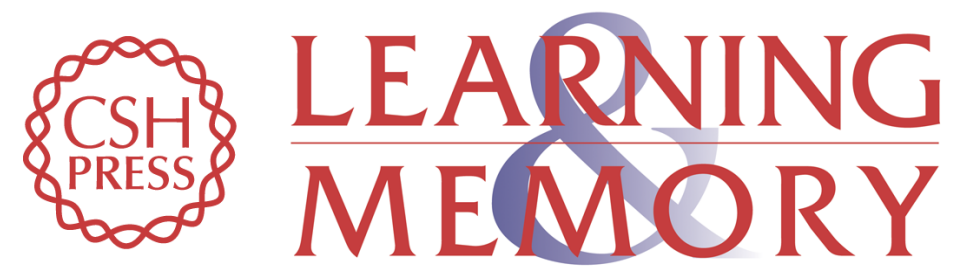

\section{Retrosplenial cortex is required for the retrieval of remote memory for auditory cues}

Travis P. Todd, Max L. Mehlman, Christopher S. Keene, et al.

Learn. Mem. 2016, 23:

Access the most recent version at doi:10.1101/Im.041822.116

\begin{aligned} & \hline References $\begin{array}{l}\text { This article cites } 62 \text { articles, } 10 \text { of which can be accessed free at: } \\ \text { http://learnmem.cshlp.org/content/23/6/278.full.html\#ref-list-1 }\end{array} \\ & \begin{aligned} \text { Creative } \\ \text { Commons } \\ \text { License }\end{aligned} \begin{array}{l}\text { This article is distributed exclusively by Cold Spring Harbor Laboratory Press for the } \\ \text { first } 12 \text { months after the full-issue publication date (see } \\ \text { http://learnmem.cshlp.org/site/misc/terms.xhtml). After } 12 \text { months, it is available under } \\ \text { a Creative Commons License (Attribution-NonCommercial } 4.0 \text { International), as } \\ \text { described at http://creativecommons.org/licenses/by-nc/4.0/. }\end{array} \\ & \begin{array}{c}\text { Receive free email alerts when new articles cite this article - sign up in the box at the } \\ \text { top right corner of the article or click here. }\end{array} \\ & \begin{array}{c}\text { Service } \\ \text { terting }\end{array}\end{aligned}$

